\title{
Differential chlorophyll blooms induced by tropical cyclones and their relation to cyclone characteristics and ocean pre-conditions in the Indian Ocean
}

\author{
NeEthu Chaсkо* (1) \\ Regional Remote Sensing Centre-East/National Remote Sensing Centre, Indian Space Research Organization, \\ Action Area 1B, Plot No. BG2, Kolkata 700 156, India. \\ e-mail: neethuchacko@gmail.com
}

MS received 12 October 2018; revised 1 April 2019; accepted 4 April 2019; published online 22 June 2019

Variability of an ocean biological response induced by tropical cyclones and the factors responsible for the differential response is relatively unexplored in the Indian ocean. The aim of the current study is to analyse and identify the difference in the amplitude of chlorophyll blooms induced by tropical cyclones during the period of 1999-2016. The relationship of the amplitude of chlorophyll blooms to the cyclone characteristics (cyclone intensity and translation speed) and the oceanographic parameters (mixed layer depth and nutricline depth) is assessed. Analysis of chlorophyll blooms induced by 28 cyclones during the study period indicated that the amplitude of the chlorophyll concentration varies irrespective of the intensity of the cyclones. The results suggest that the translation speed exhibited by the cyclone is the key factor which controls the amplitude of blooms. The slower translation speed of the cyclone enhances the bloom intensity. Another factor which controls the bloom amplitude is the pre-existing shallow mixed layer depth. A shallow mixed layer modulates the light and nutrient availability which is essential in increasing the chlorophyll concentration. It is observed that shallower nutricline depth also favours an increase in the post-cyclone chlorophyll concentration. In-situ chlorophyll observations from Bio-Argo float during cyclones Hudhud and Vardah revealed that with its slower translation speed and shallower mixed layer depth, cyclone Hudhud could induce stronger bloom than cyclone Vardah, though the intensities of both the cyclones are the same at the location of float. This study implies that relatively weaker tropical cyclones can also induce strong chlorophyll blooms under favourable conditions and not all stronger cyclones induce blooms in the Indian Ocean.

Keywords. Tropical cyclones; cyclone intensity; translation speed; mixed layer depth; nutricline depth; chlorophyll bloom.

\section{Introduction}

Tropical cyclones induce intense mixing in the upper ocean resulting in upwelling and entrainment. After the passage of a cyclone the upper ocean responds both physically and biologically which is manifested primarily as cooling of the sea surface temperature, an increase in sea surface salinity, chlorophyll blooms and an increase in primary productivity (Price 1981; Dickey et al. 1998; Subrahmanyam et al. 2002; Lin et al. 2003; Shang et al. 2008; Maneesha et al. 2012). Because of the limitations in having in-situ observations or ship-based measurements during cyclones, studies on biological responses are dependent on satellite observations. Several studies are performed to 
quantify and understand the chlorophyll blooms induced by individual cyclones (Subrahmanyam et al. 2002; Shi and Wang 2008; Liu et al. 2009; Byju and Kumar 2011; Chacko 2017). The intense mixing and upwelling induced by the cyclones results in an overall increase in the surface chlorophyll concentration either by the influx of nutrients to the upper layer or directly mixing an already existing deep chlorophyll maximum upward (Babin et al. 2004; Walker et al. 2005; Liu et al. 2009; Chacko 2017).

The biological response of the ocean to tropical cyclones depends on the cyclone characteristics such as cyclone intensity, translation speed and also oceanic subsurface conditions (Price 1981; Price et al. 1994; Zheng et al. 2008; Lin 2012; Chacko and Zimik 2018). The findings of these studies show that the translation speed and intensity of a cyclone may have different effects on the physical and biological responses of the ocean. Stronger blooms are mostly found in regions of intense cyclones as reported by Menkes et al. (2016). A pre-existing mixed layer depth is another factor which influences the upper ocean response (Price 1981). Though most of the reports on the biological response induced by tropical cyclones are based on individual cyclone cases (Subrahmanyam et al. 2002; Byju and Kumar 2011; Chacko 2017), a few researchers have analysed the inter-relationship between the cyclone forcing and the biological response by examining the cases of several cyclones. It is reported that intensity of tropical cyclones is positively correlated with the post-cyclone increase in the chlorophyll (Babin et al. 2004). However, Lin (2012) analysed the case of 11 typhoons and their effect on the chlorophyll concentration in the western North Pacific. It is also observed that even the strongest cyclone among them could not induce any notable chlorophyll bloom and only two cyclones could induce significant chlorophyll blooms. They concluded that in addition to strong wind speeds, a slow translation speed is also required to induce biological productivity in the western North Pacific Ocean. A study by Shropshire et al. (2016) reported on the regional differences in the sensitivity of wind speeds and translation speeds to cyclone-induced changes in sea surface temperature and chlorophyll in the Gulf of Mexico and Sargasso Sea. The relative importance of wind-forcing parameters and oceanic parameters in inducing chlorophyll blooms in the South China Sea and Northwest Pacific is discussed by Pan et al. (2018). The results of these studies indicate that the intensity of the cycloneinduced chlorophyll bloom varies from region to region.

The aforementioned studies have brought out the importance of cyclone characteristics and ocean pre-conditions in inducing chlorophyll blooms. However, this aspect has not been documented in detail for the Indian Ocean. A consensus on the sensitivity of the chlorophyll bloom amplitude to various parameters can be achieved by making use of the long term remotely sensed chlorophyll data. In this work, it is aimed to assess and understand the sensitivity of the cyclone-induced bloom amplitude to cyclone characteristics and ocean conditions over Indian Ocean. To shed light on this issue, instead of analysing individual or few cyclones, based on the cyclone track data available over a long period of 1999-2016, the relationship between the amplitude of chlorophyll concentration induced by tropical cyclones and the four important parameters has been explored: (i) cyclone intensity, (ii) translation speed of the cyclone, (iii) pre-existing mixed layer depth and (iv) nutricline depth. The cyclone intensity is decided based on the magnitude of the maximum sustained surface wind speeds (IMD 2003) and is herein referred to as wind speeds.

\section{Data and methods}

The six hourly cyclone track data and wind speeds are obtained from Regional Specialized Meteorological Centre (RSMC), India Meteorological Department (http://www.rsmcnewdelhi.imd.gov. in/index.php). The blended chlorophyll product from the European Space Agency (ESA) and Ocean Colour Climate Change Initiative (OC-CCI) with a spatial resolution and temporal resolution of $4 \mathrm{~km}$ and 8 days is used to assess the surface chlorophyll bloom induced by the cyclones. The OC-CCI chlorophyll product is derived from merged MODIS-Aqua, SeaWiFS, VIIRS and MERIS data. The merging of data from several satellite missions enables improved spatial coverage in the regions affected by cloud cover. More details on the OC-CCI data products can be found at http://www.esa-oceancolour-cci.org/.

The translation speed of each cyclone is calculated from the location of the cyclone following Mei et al. (2012). Temperature and salinity profiles from the ocean reanalysis data set Simple Ocean Data Assimilation (SODA v3.1) with a 
temporal and spatial resolution of 5 days and $0.25^{\circ}$ are used for computing mixed layer depths (Carton et al. 2018). The mixed layer depth is defined as the depth where the density changes based on a fixed temperature change of $0.8^{\circ} \mathrm{C}$ (Kara et al. 2000; Girishkumar et al. 2011). The climatological nitrate profiles are obtained from World Ocean Atlas 2013 (WOA13). To ascertain the amplitude of the chlorophyll bloom to the intensity of the cyclone, the region where the cyclone is intensified (highest wind speeds) is chosen as the impact zone of each cyclone. The translation speed, mixed layer depth, nutricline depth and chlorophyll concentration over this impact zone are averaged for further analysis. The pre-cyclone and post-cyclone chlorophyll concentrations are defined as the chlorophyll concentration averaged over the impact zone for a period of 8 days before and after the cyclone, respectively, following Babin et al. (2004). The amplitude of the chlorophyll bloom is defined as the difference between the post-cyclone and pre-cyclone chlorophyll concentration (hereafter referred to as delta-CHL). In this way the change in the chlorophyll concentration induced by each cyclone is computed. Observation from a BioArgo float (WMO ID: 2902114) is used to validate the results presented in this study. In addition to chlorophyll concentration, temperature and salinity observations from the float are also employed to assess the mixed layer depth. The float measures observations from 5 to $2000 \mathrm{~m}$ depth on every 5 day interval. Ekman pumping velocity is computed from daily surface winds with a spatial resolution of $25 \mathrm{~km}$ from a ASCAT scatterometer using the formula below, following Ye et al. (2013):

$$
W=\operatorname{curl}(\tau / \rho \times f),
$$

where $W, \tau, \rho$ and $f$ are the Ekman pumping velocity, wind stress, density of sea water and Coriolis parameter, respectively.

\section{Observations and analysis}

Tropical cyclones which attained the status of severe cyclonic storm during the period of 1999-2016 are considered in this study. According to the India Meteorological Department, cyclones with wind speeds between 48 and 63 knots $(1$ knot $=1.85 \mathrm{kph})$ are termed as severe cyclonic storms. A threshold wind speed of 48 knots is chosen as a minimum criterion for a cyclone to be considered for the analysis. All the cyclones during the period of 1999-2016, with their wind speeds greater than 48 knots $(89 \mathrm{~km} / \mathrm{h})$, are identified from the cyclone track data set. Due to large cloud cover in the chlorophyll data, few cyclone cases could not be included in the analysis. Excluding those cases, a total of 28 tropical cyclones are included in the analysis, 19 in the Bay of Bengal and 9 in the Arabian Sea and their tracks are shown in figure 1. Bay of Bengal experiences a large number of cyclones compared to Arabian Sea in terms of frequency and intensity (Singh et al. 2001; Balaguru et al. 2014). Bay of Bengal receives huge river discharges and rainfall when compared to Arabian Sea. This results in a fresh water cap over the Bay of Bengal which results in strong near surface haline stratification and a thin mixed layer. This peculiar stratified upper layer prevents the mixing of subsurface cooler water into the surface and thus maintains the sea surface temperature warmer. Thus, the resultant warmer sea surface temperature makes the Bay of Bengal more prone to cyclones than the Arabian Sea. A spectrum of weak to strong cyclones with their wind speeds ranging from 48 to 140 knots has been assessed. For each cyclone, the wind speed, translation speed, ratio of chlorophyll concentration, mixed layer depth and nutricline depth over the impact zone are computed and are presented in table 1 .

Among the cases considered, the post-cyclone chlorophyll concentration of four cyclones is displayed in figure 2. While cyclones Nargis and Sidr (figure $2 \mathrm{a}$ and $\mathrm{b}$, respectively) are very strong cyclones with wind speeds of 110 knots and above; cyclone Thane and the cyclone (figure $2 \mathrm{c}$ and $\mathrm{d}$ ) which occurred in Bay of Bengal during December in the year 2000 (herein referred to as Bay-Dec-2000) are relatively weaker cyclones with the maximum

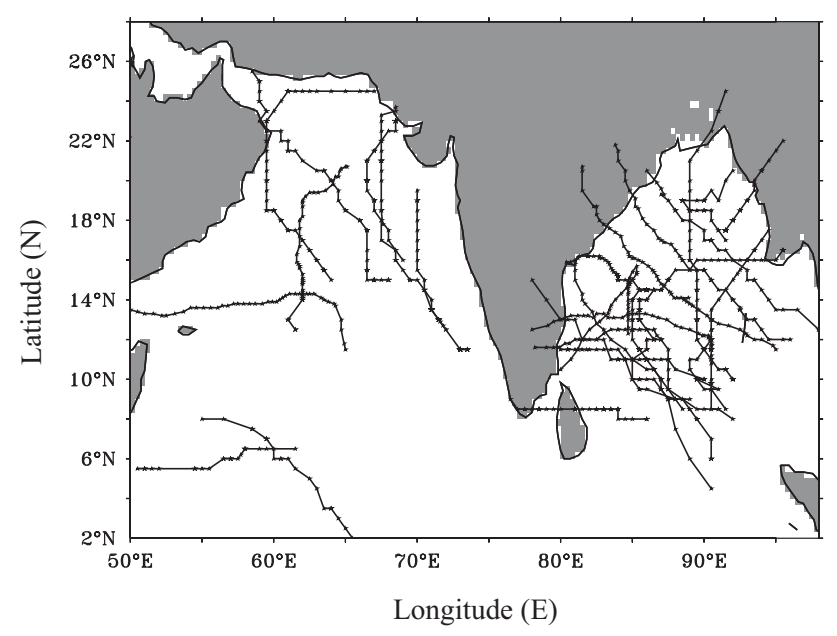

Figure 1. Tracks of the 28 tropical cyclones in the Arabian Sea and Bay of Bengal during the period of 1999-2016 analysed in this study. 
Table 1. Characteristics of the tropical cyclones arranged in their order of occurrence from year 1999 to 2016.

\begin{tabular}{|c|c|c|c|c|c|c|}
\hline Case no. & Cyclone name (date) & $\begin{array}{l}\text { Wind speed } \\
\text { (knots) }\end{array}$ & $\begin{array}{l}\text { Translation } \\
\text { speed }(\mathrm{m} / \mathrm{s})\end{array}$ & $\begin{array}{c}\text { Delta-CHL } \\
\left(\mathrm{mg} / \mathrm{m}^{3}\right)\end{array}$ & $\operatorname{MLD}(\mathrm{m})$ & $\begin{array}{l}\text { Nutricline } \\
\text { depth }(\mathrm{m})\end{array}$ \\
\hline 1 & Bay-Feb-1999 (01-03 Feb 1999) & 50 & 4.58 & 0.01447 & 50 & 60 \\
\hline 2 & As-May-1999 (16-22 May 1999) & 105 & 3.79 & 0.03797 & 18.82 & 50 \\
\hline 3 & Bay-Oct-1999 (25-31 Oct 1999) & 140 & 4.127 & 0.06496 & 13.42 & 30 \\
\hline 4 & Bay-Nov-2000 (26-30 Nov 2000) & 102 & 4 & 0.112 & 34.02 & 30 \\
\hline 5 & Bay-Dec-2000 (23-29 Dec 2000) & 90 & 2 & 0.3747 & 60 & 30 \\
\hline 6 & Bay-May-2003 (10-19 May 2003) & 75 & 2.6 & 0.06040 & 13.5 & 50 \\
\hline 7 & As-Nov-2003 (12-15 Nov 2003) & 55 & 3.24 & 0.04088 & 26.82 & 50 \\
\hline 8 & Bay-Dec-2003 (11-16 Dec 2003) & 55 & 4.12 & 0.01745 & 44.37 & 30 \\
\hline 9 & As-May-2004 (05-10 May 2004) & 55 & 3.7 & 0.04350 & 26 & 50 \\
\hline 10 & Bay-May-2004 (16-19 May 2004) & 90 & 5.00926 & 0.01119 & 12.53 & 20 \\
\hline 11 & ONIL (30 Sep-03 Oct 2004) & 55 & 2.98 & 0.1434 & 15 & 10 \\
\hline 12 & Agni (29 Nov-02 Dec 2004) & 55 & 4 & 0.07864 & 31.15 & 50 \\
\hline 13 & Mala (25-29 Apr 2006) & 100 & 3.178 & 0.1003 & 11.18 & 50 \\
\hline 14 & Gonu (01-05 Jun 2007) & 127 & 3.814 & 0.05314 & 20.33 & 30 \\
\hline 15 & Sidr (11-16 Nov 2007) & 115 & 4.365 & 0.07453 & 20.32 & 30 \\
\hline 16 & Nargis (27 Apr-02 May 2008) & 110 & 5.09 & 0.1037 & 12.44 & 50 \\
\hline 17 & Phet (31 May-05 Jun 2010) & 85 & 2.54 & 0.1412 & 16.77 & 5 \\
\hline 18 & Giri (20-23 Oct 2010) & 105 & 4 & -0.04653 & 25.11 & 30 \\
\hline 19 & Jal (01-07 Nov 2010) & 60 & 5.93 & 0.09071 & 24.51 & 30 \\
\hline 20 & Thane (25-31 Dec 2011) & 75 & 3.3 & 0.3029 & 44.12 & 30 \\
\hline 21 & Phailin (08-12 Oct 2013) & 115 & 3.089 & 0.1747 & 11.19 & 30 \\
\hline 22 & Helen (19-22 Nov 2013) & 55 & 2.037 & 0.3956 & 22.72 & 30 \\
\hline 23 & Madi (06-13 Dec 2013) & 65 & 2.14 & 0.4463 & 29.82 & 30 \\
\hline 24 & Hudhud (07-12 Oct 2014) & 100 & 2.393 & 0.3716 & 17.83 & 30 \\
\hline 25 & Nilofar (25-30 Oct 2014) & 110 & 4.5 & 0.1353 & 22.69 & 20 \\
\hline 26 & Chapala (28 Oct-03 Nov 2015) & 115 & 4.5 & 0.01 & 39.54 & 20 \\
\hline 27 & Megh (05-10 Nov 2015) & 95 & 6.43 & -0.02579 & 23.8 & 20 \\
\hline 28 & Vardah (06-12 Dec 2016) & 70 & 3.19 & 0.1835 & - & 30 \\
\hline
\end{tabular}

The cyclones which are not named are denoted as 'basin name-month-year' for easier usage in the text. AS and Bay denote the Arabian Sea and Bay of Bengal, respectively.

sustained wind speeds of 75 and 90 knots, respectively. It can be noted from the figure that the amplitude of the chlorophyll bloom induced by the relatively weaker cyclones (Thane and Bay-Dec2000 ) is high when compared to that of the blooms induced by the stronger cyclones (Nargis and Sidr). The chlorophyll concentration along the track of cyclone Nargis remains $\sim 0.2 \mathrm{mg} / \mathrm{m}^{3}$. A high concentration of chlorophyll can be observed in the Gulf of Martaban region. However, Shi and Wang (2008) reported that the magnitude of the chlorophyll concentration before and after Nargis remained roughly the same in the Gulf of Martaban region. This suggests that stronger winds of Nargis could not induce a significant biological response in the ocean. Similarly, the post-cyclone chlorophyll concentration along the track of cyclone Sidr is $1 \mathrm{mg} / \mathrm{m}^{3}$. However, the chlorophyll bloom intensity in the case of weaker cyclones Thane and Bay-Dec-2000 is much higher $>2.5 \mathrm{~m} \mathrm{mg} / \mathrm{m}^{3}$. Similar differential chlorophyll bloom responses are observed in other cyclone cases also. This shows that the amplitude of the chlorophyll concentration varies irrespective of the intensity of the cyclones. The following section discusses on the relationship between the bloom amplitude to cyclone characteristics and oceanic conditions.

\subsection{Cyclone characteristics: cyclone intensity and translation speed}

In order to understand the relationship between the amplitude of the chlorophyll bloom and the cyclone intensity, figure 3(a) shows the scatter plot of delta-CHL versus the wind speeds of the cyclones. The figure points out that the amplitude of the chlorophyll bloom is not efficiently affected 


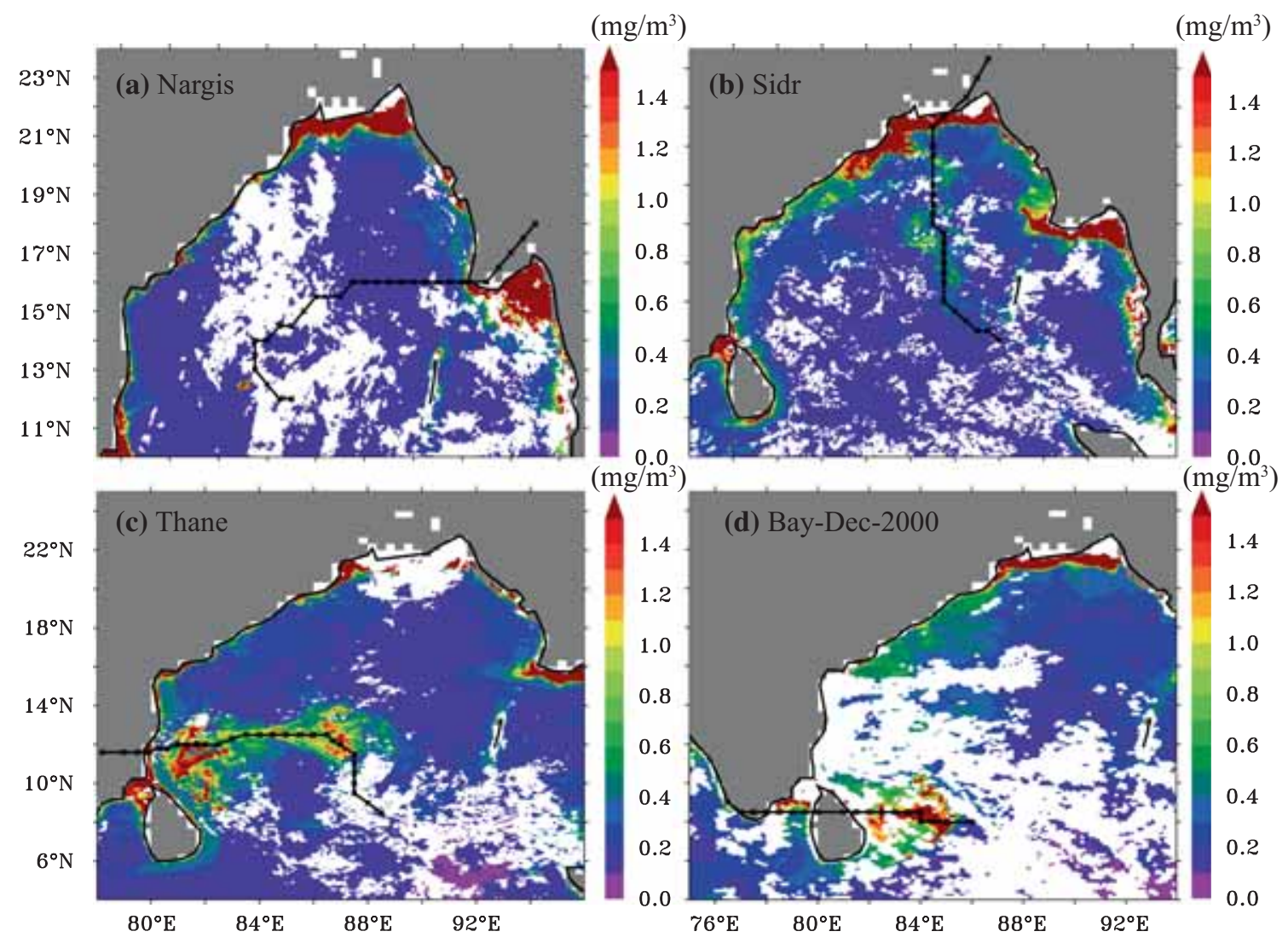

Figure 2. Chlorophyll concentration $\left(\mathrm{mg} / \mathrm{m}^{3}\right)$ averaged for 8 days after the cyclones: (a) Nargis, (b) Sidr, (c) Thane and (d) Bay-Dec-2000. Tracks of the cyclones are overlaid on each plot.

by the intensity of the cyclones alone in the Indian Ocean. The scatter plot between the delta-CHL and translation speed of the cyclone is shown in figure 3(b). It can be seen that a negative relationship exists between the delta-CHL and the translation speed with a correlation coefficient of -0.69 and a coefficient of determination $\left(R^{2}\right)$ of 0.47. The relationship is observed as significant with the confidence level of $95 \%\left(P<4.8 \times 10^{-3}\right)$. This implies that the amplitude of the chlorophyll bloom increases with reduction in translation speeds. From table 1, the lowest translation speed $(\sim 2 \mathrm{~m} / \mathrm{s})$ is observed for cyclone Bay-Dec-2000, and it could induce a delta-CHL of $0.3747 \mathrm{mg} / \mathrm{m}^{3}$ which denotes a strong bloom. It is worth noting that Bay-Dec-2000 with its wind speed of $\sim 90$ knots could induce more chlorophyll concentration than 1999 supercyclone (delta-CHL $=0.06496$ ) with a wind speed of 140 knots. Similar are the cases of cyclones Helen and Madi with a low translation speed of $\sim 2.1 \mathrm{~m} / \mathrm{s}$ which could induce higher delta-CHL. Though the wind speeds of Helen and Madi are much lower $\sim 55$ to 65 knots, it is observed that the delta-CHL values are much higher than many other cyclones with higher wind speeds. Cyclones Sidr, Phailin and Chapala have a wind speed magnitude of 115 knots. Among these three cyclones, the maximum delta-CHL occurs for the cyclone Phailin with the least translation speed of $3 \mathrm{~m} / \mathrm{s}$. Table 1 shows the cases of other cyclones (Hudhud and Mala; Bay-Dec-2000 and Bay-May2004) with the same wind speeds. It can be observed that the cyclone with the low translation speed has the higher delta-CHL. Delta-CHL noted in the case of Hudhud (translation speed $\sim 2.3 \mathrm{~m} / \mathrm{s}$ ) is higher than that in the case of Mala (translation speed $\sim 3.17 \mathrm{~m} / \mathrm{s}$ ) though both are having a wind speed of $\sim 100$ knots. It can be seen from the table that as the translation speed increases, the delta-CHL becomes less compared to the cases with slower translation speeds. Comparing the relationship between the characteristics of the cyclone intensity and translation speed, it is revealed that an increase in the chlorophyll concentration is more sensitive to the translation speed of the cyclone rather than the cyclone intensity. This shows that the amplitude of the chlorophyll bloom following a cyclone is strongly dependent on the translation speed of the cyclone than the cyclone intensity. Slower moving cyclones impart more 

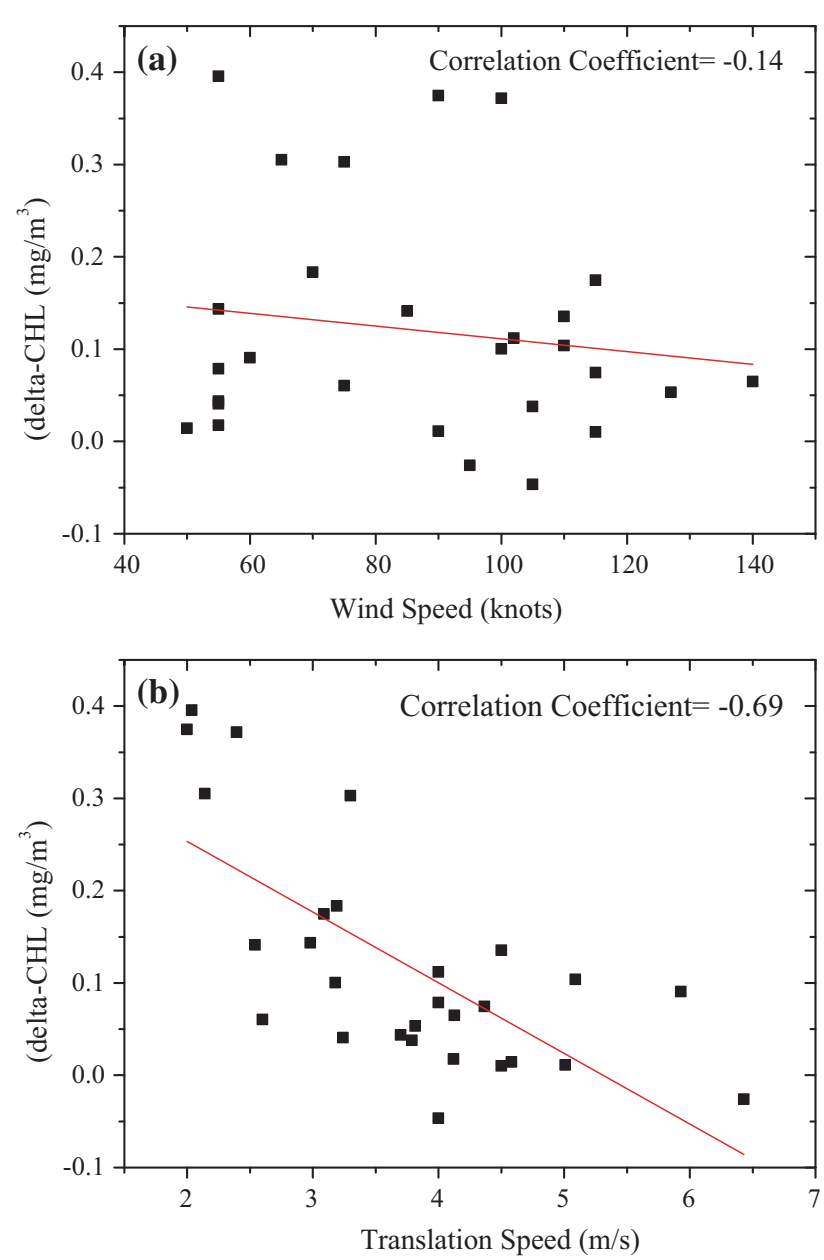

Figure 3. Scatter plots of (a) maximum surface wind speed $($ knots; $1 \mathrm{knot}=0.514 \mathrm{~m} / \mathrm{s})$ and $(\mathbf{b})$ translation speed $(\mathrm{m} / \mathrm{s})$ to the delta-CHL $\left(\mathrm{mg} / \mathrm{m}^{3}\right)$ of the 28 tropical cyclones assessed.

momentum into the ocean which results in the enhanced vertical mixing of the subsurface water into the surface layers (Sun et al. 2010; Mei et al. 2015). It is reported that, in the Gulf of Mexico, the chlorophyll response following a cyclone is more sensitive to the translation speed compared to the wind speed (Shropshire et al. 2016). Similar results are found in the case of Hurricanes Katrina, Rita and Wilma, where the slower translation speeds of Wilma and Katrina resulted in enhanced productivity (Gierach and Subrahmanyam 2008) than the stronger Hurricane Rita. The case studies of these three cyclones could not illustrate any significant influence of the intensity of cyclone to the amplitude of the chlorophyll response. Lin (2012) reported that in the Western North Pacific, cyclone intensity is the major factor which influences the chlorophyll bloom with additional conducive factors like slower translation speed which can enhance the bloom. However, this analysis shows that cyclone intensity alone is not responsible for inducing the chlorophyll blooms in the Indian Ocean. It can be noticed that cyclones with less wind speeds also induce as much as or even more than the amplitude of chlorophyll blooms induced by cyclones with higher wind speeds (figure 2 and table 1). Thus, there exists a regional difference in the sensitivity of cyclone characteristics to the amplitude of chlorophyll blooms.

\subsection{Ocean pre-conditions: mixed layer depth and nutricline depth}

The chlorophyll concentration depends on the interplay between the light availability and nutrient concentration (Walker et al. 2005; Gierach and Subrahmanyam 2008). The mixed layer depth is a key parameter which can alter these two factors. The relationship between the mixed layer depth and chlorophyll has been assessed by many researchers (Matsumoto et al. 2014; Yasuda and Watanabe 2007; Itoh et al. 2015). A shallower mixed layer maintains higher nutrient concentration below it and facilitates ambient light conditions which are essential for the new production (Yasuda and Watanabe 2007; Lin 2012; Pan et al. 2018). Light intensity is a major factor for increasing the ocean biological productivity which is facilitated by shallower mixed layer depths. To examine the sensitivity of chlorophyll concentration induced by cyclones to the pre-existing mixed layer depth, pre-cyclone mixed layer depths are computed and compared with the respective deltaCHL values (table 1 ). The SODA data, which are used for the computation of the mixed layer depth, are available only until 2015. Because of this, the mixed layer depth for the cyclone Vardah which occurred in 2016 could not be computed and included in the analysis. It can be seen from table 1 that mixed layer depths are relatively shallower $(<30 \mathrm{~m})$ for most of the cyclones. Figure 4 shows the scatter plot between the mixed layer depths and the delta-CHL computed for the cyclone cases. A negative relationship exists between the mixed layer and deltaCHL excluding a few outliers corresponding to cyclones, viz., Bay-Dec-2000, Thane, Helen, Madi and Hudhud. The regression is computed excluding these outliers where a correlation coefficient of -0.43 is noted while the $R^{2}$ is 0.43 . The $P$ value for the fitting at the $95 \%$ confidence level is 0.045 . Though the outlier cases of Bay-Dec-2000 and Thane have deeper mixed layer depths (table 1), they exhibit slower translation speeds which explain their higher 


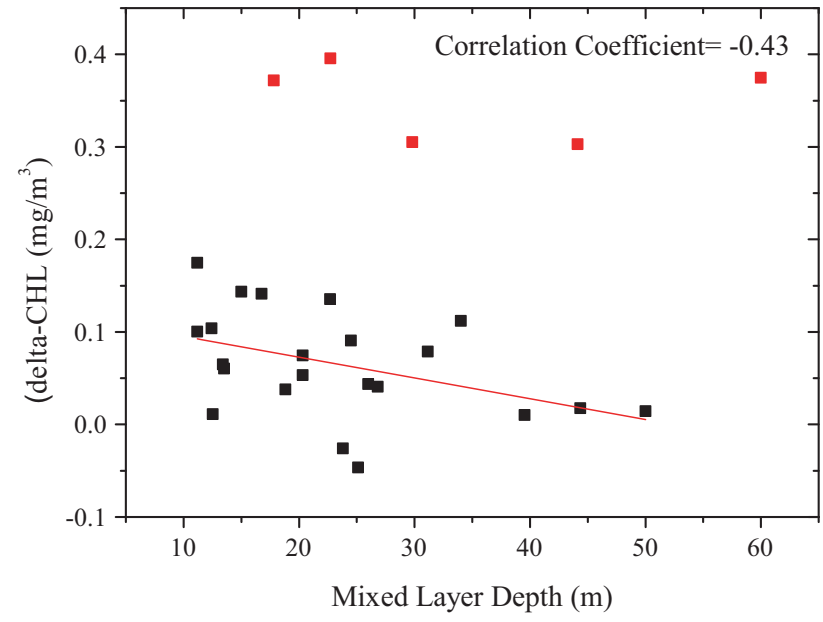

Figure 4. Scatter plot between the mixed layer depth (m) and delta-CHL $\left(\mathrm{mg} / \mathrm{m}^{3}\right)$ of the 17 cyclones assessed.

delta-CHL. The other three outlier cyclones also have slower translation speeds in addition to shallower mixed layer depths (table 1) which resulted in increasing their chlorophyll amplitudes significantly. In general, it can be noted that shallower mixed layer depths correspond to strong post-cyclone chlorophyll blooms, which substantiate the importance of light intensity for blooms to occur.

Another parameter which influences the chlorophyll boom amplitude is the nutricline depth i.e., the depth where the nitrate concentrations begin to increase from near zero levels. This depth is extracted from the climatological nitrate profile corresponding to the respective month of occurrence of each cyclone averaged over their impact zone. The vertical nitrate profiles of few cyclones averaged over their respective impact zones are plotted in figure 5. From each profile, the depth at which the nitrate concentration begins to increase from near zero level is taken as the nutricline depth. The nutricline depths of all the cyclones analysed in this study are thus obtained and are listed in table 1. Due to the physical mixing of the water column, the upper mixed layer penetrates the nutricline, thereby providing a source of nutrients to the euphotic zone. The climatological nitrate concentration in the upper $100 \mathrm{~m}$ for few cyclone cases is shown in figure 5. The mean nutricline depth calculated for each of the cyclones is almost shallow $(\sim 20$ to $30 \mathrm{~m})$ except for a few cyclones for which the depth of the nutricline is very deep $\sim 50$ to $60 \mathrm{~m}$. A consequence of the deeper nutricline is that during physical mixing, the penetration of the mixed layer is unlikely to occur at these deeper levels. It is reported that the
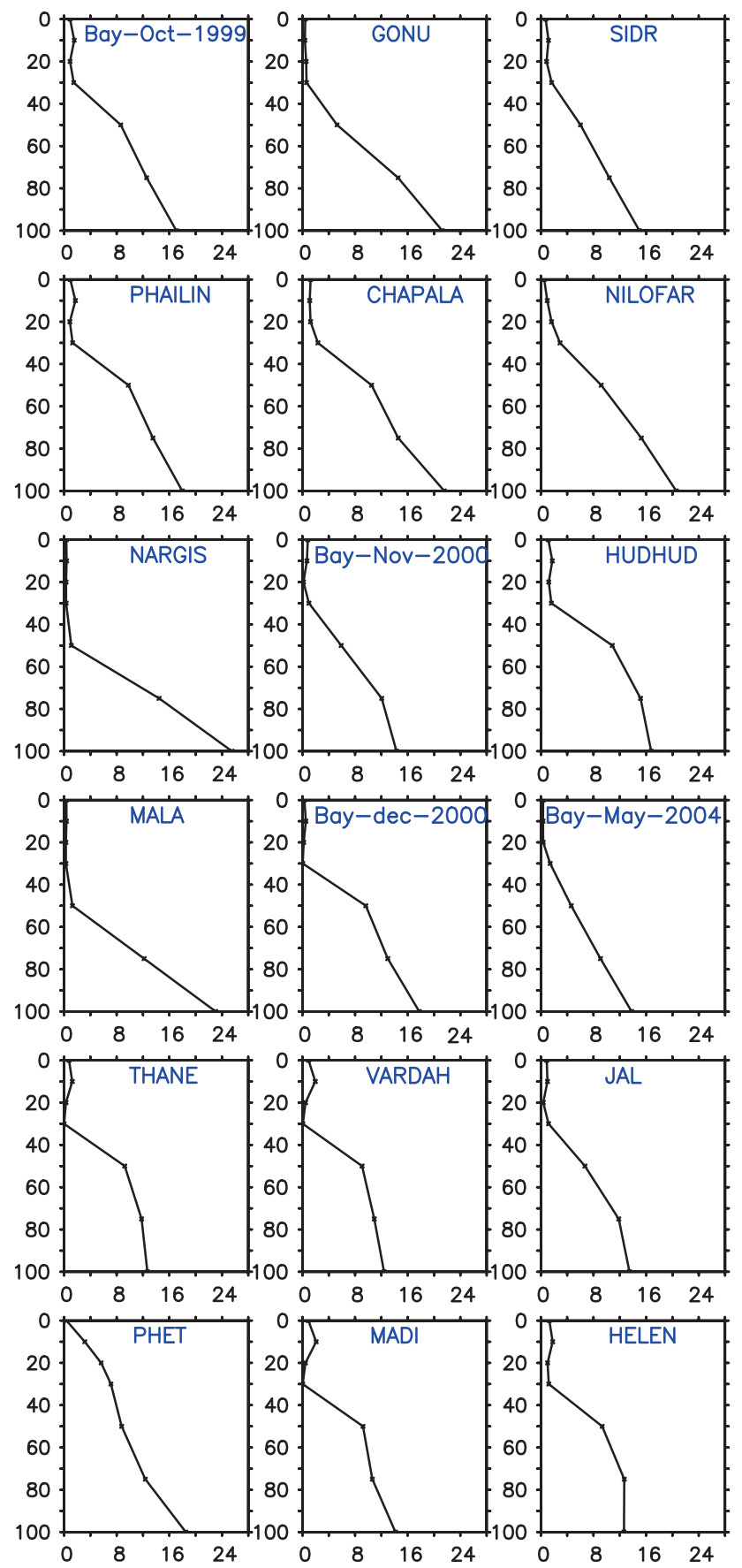

Figure 5. Vertical profiles of climatological nitrate concentration $(\mu \mathrm{mol} / \mathrm{l})$ averaged over the impact zone for few cyclones in the upper $100 \mathrm{~m}$ depth.

productivity is negatively correlated with the depth of the nutricline (Cermano et al. 2008). It can be noted that for most cases when the nutricline is shallower, the delta-CHL values are higher whereas when the nutricline is deeper, the deltaCHL is relatively lower. As in most of the cases nutricline is shallower, a shallow mixed layer depth ensues nitrate supply into the upper oceanic layer which can result in new production and enhanced 
chlorophyll concentration. Thus it can be inferred that a shallower nutricline depth is favourable to stronger blooms and vice versa. The chlorophyll bloom followed by cyclones is due to the combined effect of entrainment of subsurface chlorophyll and new production induced by the upwelled nutrients (Babin et al. 2004; Mei et al. 2015; Chacko 2017). Hence, it is worth mentioning that the depth of the subsurface chlorophyll maximum also determines the amplitude of the chlorophyll blooms in addition to the nutricline depth. However, due to the lack of subsurface chlorophyll observations, assessing the relationship between the chlorophyll bloom amplitude and the depth of the subsurface chlorophyll maximum is not feasible.

From table 1, it can be observed that cyclones with very less translation speeds $(<3 \mathrm{~m} / \mathrm{s})$ are observed having higher delta-CHL. Some of the cases are Bay-Dec-2000, Helen, Madi, Hudhud and Phet. Similarly, when the translation speeds are higher $(>4 \mathrm{~m} / \mathrm{s})$ delta-CHL values are less (Giri, Bay-Oct-1999, Sidr, Chapala, Megh, Jal, etc.). This can be attributed to the longer forcing time induced by the slow moving cyclones and the higher momentum it imparts to the ocean which results in stronger vertical mixing and stronger blooms. It can also be noted that cyclones with slower translation speeds exhibited higher deltaCHL even if their pre-existing mixed layer depths are deeper. For example, even though the mixed layer depths of Thane and Bay-Dec-2000 are deeper (44 and $55 \mathrm{~m}$, respectively), the lower translation speed of cyclones resulted in enhancing the bloom. Among the cyclones with the same intensity/wind speeds, those with the slowest translation speed are observed as having higher deltaCHL substantiating the importance of the slower translation speed in the variability of the chlorophyll bloom amplitude.

\subsection{Case studies during tropical cyclones Hudhud and Vardah: observations from Bio- Argo}

The above analysis is based on satellite observations of surface chlorophyll. In this section, in-situ observations from Bio-Argo float are used to validate the results presented in the above section. A Bio-Argo float was fortuitously present very close to the tracks of cyclones Hudhud and Vardah. Figure 6(a and b) presents the post-
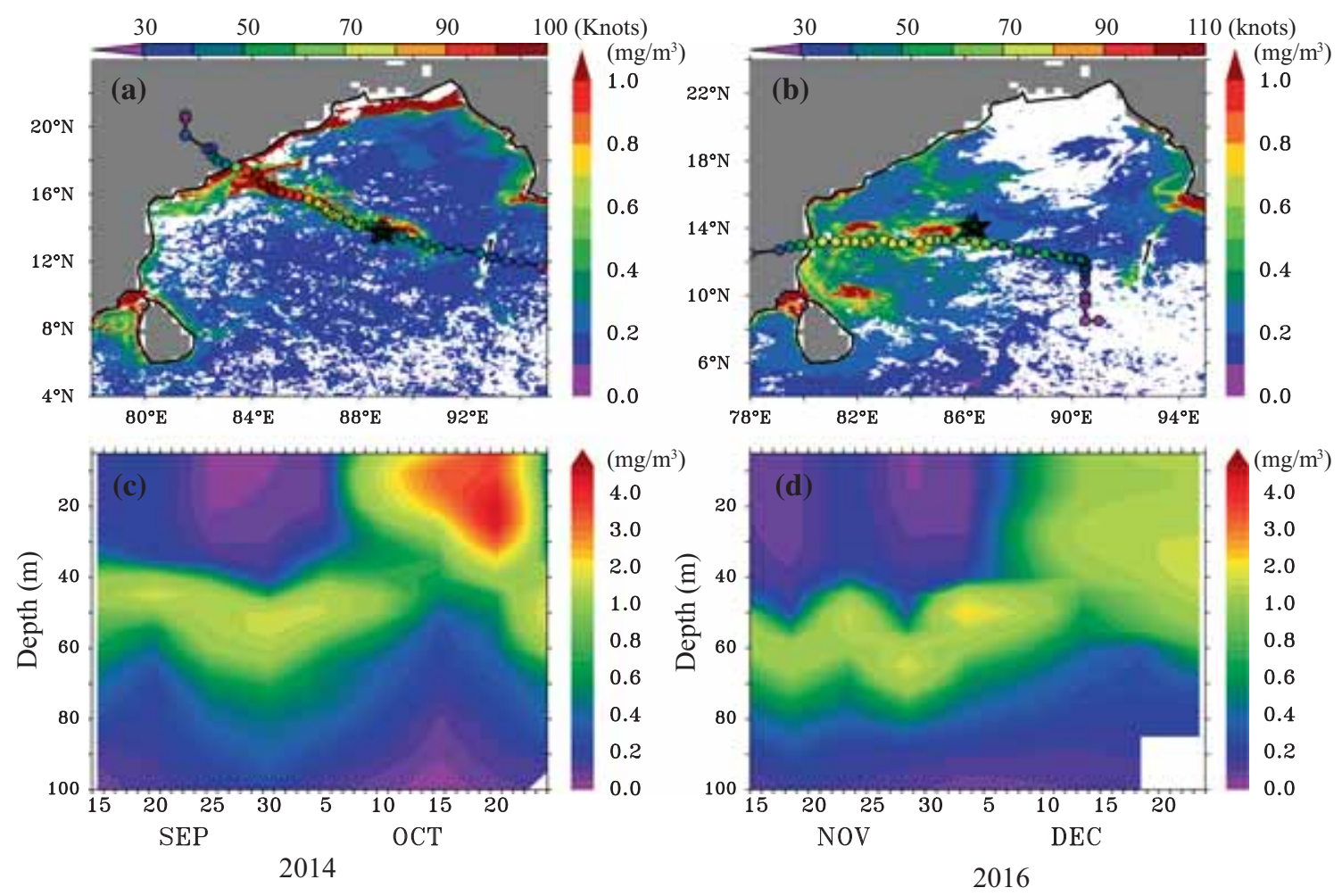

Figure 6. Post-cyclone chlorophyll concentration $\left(\mathrm{mg} / \mathrm{m}^{3}\right.$ ) for cyclones (a) Hudhud (7-12 October 2014) and (b) Vardah (6-12 December 2016). Tracks of the cyclones are overlaid and the star symbol denotes the position of the Bio-Argo float during the cyclones. Time evolution of subsurface chlorophyll concentration $\left(\mathrm{mg} / \mathrm{m}^{3}\right)$ observed by Bio-Argo float during (c) Hudhud and (d) Vardah. 
Table 2. Comparison of characteristics of tropical cyclones Hudhud (2014) and Vardah (2016).

\begin{tabular}{lcccccc}
\hline & $\begin{array}{c}\text { Wind speed } \\
(\mathrm{knots})\end{array}$ & $\begin{array}{c}\text { Translation } \\
\text { speed }(\mathrm{m} / \mathrm{s})\end{array}$ & MLD $(\mathrm{m})$ & $\begin{array}{c}\text { Nutricline } \\
\text { depth }(\mathrm{m})\end{array}$ & $\begin{array}{c}\text { Delta-CHL } \\
\left(\mathrm{mg} / \mathrm{m}^{3}\right)\end{array}$ & $\begin{array}{c}\text { Ekman pumping } \\
\text { velocity }\left(10^{-6} \mathrm{~m} / \mathrm{s}\right)\end{array}$ \\
\hline Hudhud & 65 & 2.14 & 20 & 30 & 3.08 & 6.523 \\
Vardah & 65 & 4.5 & 40 & 30 & 0.7 & 4.22 \\
\hline
\end{tabular}

cyclone chlorophyll bloom induced by cyclones Hudhud (7-12 October 2014) and Vardah (6-12 December 2016) from OC-CCI along with the position of the Bio-Argo floats during the period of the cyclones. Figure 6(c and d) shows the time evolution of subsurface chlorophyll for the two cyclones observed by the Bio-Argo float. It can be seen that the concentration of chlorophyll induced by Hudhud reaches up to $4.5 \mathrm{mg} / \mathrm{m}^{3}$ whereas for Vardah it is up to $2 \mathrm{mg} / \mathrm{m}^{3}$. The near surface chlorophyll concentration measured by the BioArgo floats at a depth of $5 \mathrm{~m}$ also depicts a significant difference in the concentration of the chlorophyll induced by both the cyclones. The delta-CHL values for Vardah and Hudhud at the near surface are 0.7 and $3.08 \mathrm{mg} / \mathrm{m}^{3}$ respectively. While Hudhud exhibited the maximum surface winds of 100 knots in its lifetime and achieved the status of extremely severe cyclonic storm; Vardah reached the status of severe cyclonic storm with its maximum surface wind speed of 70 knots. However, it is worth noting that at the location of the Bio-Argo float, the maximum surface wind speeds of Vardah and Hudhud are similar $\sim 65$ knots. Thus, the wind forcing at this location by the two cyclones is similar. The pre-existing mixed layer depths, translation speed, nutricline depth and Ekman pumping velocity during Hudhud and Vardah are computed and presented in table 2. It can be noted that at these locations, the translation speed of Hudhud is $2 \mathrm{~m} / \mathrm{s}$ whereas that of Vardah is $4 \mathrm{~m} / \mathrm{s}$. The pre-existing mixed layer depth of Hudhud $(20 \mathrm{~m})$ is shallower when compared to that of Vardah $(40 \mathrm{~m})$. The Nutricline depth is $30 \mathrm{~m}$ for both the cyclones. The Ekman pumping velocity which is an indicator of the strength of upwelling is computed during Hudhud $\left(6.523 \times 10^{-6} \mathrm{~m} / \mathrm{s}\right)$ and is quite large when compared to that of Vardah $\left(4.22 \times 10^{-6} \mathrm{~m} / \mathrm{s}\right)$. This substantiates that the slower translation speed of a cyclone imparts enhanced vertical mixing of the subsurface water into the surface layers. Thus, the conducive factors of a slower translation speed and pre-existing shallower mixed layer depth have resulted in inducing strong chlorophyll blooms in the case of
Hudhud though its intensity is as much as Vardah at the location of the observation.

\section{Conclusions}

Previous research has shown that the biological response followed by a cyclone is complex, varying regionally and is highly dependent on the cyclone characteristics and the underlying pre-existing oceanic conditions. However, the variations in the amplitude of chlorophyll blooms induced by tropical cyclones are not yet described in detail for the Indian Ocean. In this study, the differential chlorophyll blooms induced by tropical cyclones are discussed, along with the sensitivity of cyclone characteristics (cyclone intensity/wind speed and translation speed) and the pre-existing oceanic conditions (mixed layer depth and nutricline depth) on the bloom amplitude. Analysis of 28 tropical cyclone cases during the period of 1999-2016 reveals that there is strong variability in the amplitude of chlorophyll blooms induced by cyclones. It is observed that cyclones with relatively lower wind speeds can induce stronger blooms compared to cyclones with higher wind speeds. Thus, the intensity of cyclones alone is not the key factor for determining the amplitude of the blooms in the Indian Ocean. The results show strong control of the cyclone translation speed on the bloom amplitude than the intensity of the cyclone. The cyclone cases with the slower translation speed resulted in stronger blooms compared to the cases with higher translation speeds. Among all the four parameters considered, the translation speed of the cyclone can be considered as the key factor since it directly affects the response on the upper ocean by increasing the forcing time thereby inducing stronger blooms. Thus, the slower translation speed (correlation coefficient of -0.69 at 95 confidence level) results in strong chlorophyll blooms. Similarly, the shallow mixed layer and nutricline depth are also observed as conducive for inducing stronger chlorophyll blooms under cyclone forcing. The analysis of 28 cyclones over two decades of time 
(1999-2016) demonstrates that relatively weaker tropical cyclones (less wind speeds) can also induce strong chlorophyll blooms under favourable conditions and not all strong cyclones (higher wind speeds) induce significant blooms.

\section{Acknowledgements}

The sources for various data used in this study are provided in the 'Data and methods' section. SODA data are downloaded from http://apdrc.soest. hawaii.edu/data/data.php. World Ocean Atlas nitrate profiles are downloaded from https://www. nodc.noaa.gov/OC5/woa13. The Bio-Argo data are collected and made freely available by the International Argo Program and the national programs that contribute to it. The figures used in this paper are plotted in Ferret and Origin. Thanks to two anonymous reviewers for their suggestions and comments which helped in improving the quality of this paper.

\section{References}

Babin S M, Carton J A, Dickey J A and Wiggert J D 2004 Satellite evidence of hurricane-induced phytoplankton blooms in an oceanic desert; J. Geophys. Res. 109 C03043, https://doi.org/10.1029/2003JC001988.

Balaguru K S, Taraphdar S, Leung L R and Foltz G R 2014 Increase in the intensity of post monsoon Bay of Bengal tropical cyclones; Geophys. Res. Lett. 41 3594-3601, https:/ / doi.org/10.1002/2014GL060197.

Byju P and Kumar P S 2011 Physical and biological response of the Arabian Sea to tropical cyclone Phyan and its implications; Mar. Env. Res. 71(5) 325-330.

Carton J A, Chepurini G A and Chen L 2018 SODA3: A new ocean climate reanalysis; J. Clim. 31 6967-6983, https:// doi.org/10.1175/JCLI-D-18-0149.1.

Cermano P, Dutkiewicz S, Harris R P, Follows M, Schofield O and Falkowski P G 2008 The role of nutricline depth in regulating the ocean carbon cyclone; Proc. Nat. Acad. Sci. USA 105 20,344-20,349, https://doi.org/10.1073/pnas. 0811302106.

Chacko N 2017 Chlorophyll bloom in response to tropical cyclone Hudhud in the Bay of Bengal: Bio-Argo subsurface observations; Deep Sea Res. 1124 66-72, https://doi.org/ 10.1016/j.dsr.2017.04.010.

Chacko N and Zimik L 2018 Effect of cyclone Thane in the Bay of Bengal explored using moored buoy observations and multi-platform satellite data; J. Indian Soc. Remote Sens. 46(5) 821-828, https://doi.org/10.1007/s12524-0170748-9.

Dickey T, Frye D, McNeil J, Manov D, Nelson N, Sugurdson D, Jannasch H, Siegal D, Michaels T and Johnson R 1998 Upper-ocean temperature response to Hurricane Felix as measured by the Bermuda Testbed Mooring; Mon. Weather Rev. 126 1195-1201, https://doi.org/10.1175/15200493(1998)126<1195:UOTRTH >2.0.CO;2.

Gierach M M and Subrahmanyam B 2008 Biophysical responses of the upper ocean to major Gulf of Mexico hurricanes in 2005; J. Geophys. Res. 113 C04029, https:// doi.org/10.1029/2007JC004419.

Girishkumar M S, Ravichandran M, McPhaden M J and Rao R R 2011 Intraseasonal variability in barrier layer thickness in the south central Bay of Bengal; J. Geophys. Res. 116 C03009.

IMD 2003 Cyclone manual; IMD, New Delhi.

Itoh S, Yasuda I, Saito H, Tsuda A and Komatsu K 2015 Mixedlayer depth and chlorophyll a: Profiling float observations in the Khuroshio-Oyashio extension region; J. Mar. Syst. 151 1-14.

Kara A B, Rochford P A and Hurlbutt H E 2000 Mixed layer depth variability and barrier layer formation over the North Pacific Ocean; J. Geophys. Res. 105(C7) 16,783-16,801.

Lin I I 2012 Tyhoon induced phytoplankton blooms and primary productivity increase in the western North Pacific subtropical ocean; J. Geophys. Res. 117 C03039, https:// doi.org/10.1029/2011JC007626.

Lin I I, Liu W T, Wu C C, Wong G T F, Hu C, Chen Z, Liang W D, Yang Y and Liu K K 2003 New evidence for enhanced ocean primary production triggered by tropical cyclone; Geophys. Res. Lett. 30(13) 1718, https://doi.org/10.1029/ 2003 GL017141.

Liu X, Wang M and Shi W 2009 A study of a Hurricane Katrina-induced phytoplankton bloom using satellite observations and model simulations; J. Geophys. Res. 114 C03023, https://doi.org/10.1029/2008JC004934.

Maneesha K, Murty V S N, Ravichandran M, Lee T, Yu W and Mcphaden M J 2012 Upper ocean variability in the Bay of Bengal during the tropical cyclones Nargis and Laila; Prog. Oceanogr. 106 49-61, https://doi.org/10.1016/j. pocean.2012.06.006.

Matsumoto K, Honda M C, Sasaoka K, Wakita M, Kawakami H and Watanabe S 2014 Seasonal variability of primary production and phytoplankton biomass in the western Pacific subarctic gyre: Control by light availability within the mixed layer; J. Geophys. Res. Oceans 119 6523-6534.

Mei W, Lein C C, Lin I I and Xie S P 2015 Tropical cycloneinduced ocean response: A comparative study of the South China Sea and tropical Northwest Pacific; J. Clim. 28 5952-5968, https://doi.org/10.1175/JCLI-D-14-0065.11.

Mei W, Pasquero C and Primeau F 2012 The effect of translation speed upon the intensity of tropical cyclones over the tropical ocean; Geophys. Res. Lett. 39 L07801, https://doi.org/10.1029/2011GL050765.

Menkes C E, Lengaigne M, Levy M, Ethe C, Bopp L, Aumont O, Vincent E, Vialard J and Jullien S 2016 Global impact of tropical cyclones on primary production; Global Biogeochem. Cycles 30 767-786, https://doi.org/10.1002/ 2015 GB005214.

Pan J, Huang L, Devlin A T and Lin H 2018 Quantification of typhoon-induced phytoplankton blooms using satellite multi-sensor data; Remote Sens. (Basel) 10 318, https:// doi.org/10.3390/rs/10020318.

Price J F 1981 Upper ocean response to a hurricane; J. Phys. Oceanogr. 11 153-175, https://doi.org/10.1175/15200485(1981)011<UORTAH>2.0.CO;2. 
Price J F, Sanford T B and Forristall G Z 1994 Forced stage response to a moving hurricane; J. Phys. Oceanogr. 24 233-260, https://doi.org/10.1175/15200485(1994)024<0233: FSRTAM $>2.0 . \mathrm{CO} ; 2$.

Shang S, Li L, Sun F, Wu J, Hu C, Chen D, Ning X, Qiu Y, Zhang $\mathrm{C}$ and Shang S 2008 Changes of temperature and biooptical properties in the South China Sea in response to Typhoon Lingling, 2001; Geophys. Res. Lett. 35 L10602, https://doi.org/10.1029/2008GL033502.

Shi W and Wang M 2008 Three dimensional observations from MODIS and CALIPOS for ocean responses to cyclone Nargis in the Gulf of Martaban; Geophys. Res. Lett. 35 L21603, https://doi.org/10.1029/2008GL035279.

Shropshire T, Li Y and He R 2016 Storm impact on sea surface temperature and chlorophyll a in the Gulf of Mexico and Sargasso Sea based on daily cloud-free satellite data reconstructions; Geophys. Res. Lett. 43, https://doi.org/ 10.1002/2016GL071178.

Singh O T, Khan M A and Rahman M S 2001 Has the frequency of intense cyclones increased in the north Indian Ocean? Curr. Sci. 80(4) 575-580.

Subrahmanyam S, Rao K H, Rao N S, Murty V S N and Sharp R J 2002 Influence of a tropical cyclone on Chlorophyll-a concentration in the Arabian Sea; Geophys. Res. Lett. 29(22) 2065, https://doi.org/10.1029/2002GL015892.

Sun L, Yang Y J, Xian T, Lu Z and Fu Y F 2010 Strong enhancement of chlorophyll a concentration by a weak typhoon; Mar. Ecol. Prog. Ser. 404 39-50, https://doi.org/ 10.3354/meps08477.

Walker N D, Leben R R and Balasubramaniam S 2005 Hurricane-forced upwelling and chlorophyll a enhancement within cold-core cyclones in the Gulf of Mexico; Geophys. Res. Lett. 32 L18610, https://doi.org/10.1029/2005GL023716.

Yasuda I and Watanabe T 2007 Chlorophyll a variation in the Khuroshio Extension revealed with a mixed-layer tracking float: Implication on the long-term change of Pacific saury (Cololabis saira); Fish. Oceanogr. 16 482-488, https://doi. org/10.1111/j.1365-2419.2007.00457.x.

Ye H J, Sui Y, Tang D L and Afanasyev Y D 2013 A subsurface chlorophyll a bloom induced by typhoon in the South China Sea; J. Mar. Syst. 128 138-145, https://doi. org/10.1016/j.jmarsys.2013.04.010.

Zheng Z W, Ho C R and Kuo N J 2008 Importance of preexisting oceanic conditions to upper ocean response induced by super typhoon Hai-Tang; Geophys. Res. Lett. 35 L20603, https://doi.org/10.1029/2008GL0355.

\section{Corresponding editor: C Gnanaseelan}

